\title{
Transient stability analysis with equal-area criterion for out of step detection using phasor measurement units
}

\author{
A. Y. Abdelaziz ${ }^{*}$, Amr M. Ibrahim ${ }^{1}$, Zeinab G. Hasan ${ }^{2}$ \\ ${ }^{1 *}$ Electrical Power and Machines Department, Ain Shams University, Cairo, EGYPT \\ ${ }^{2}$ Electrical Power Department, the Higher Institute of Engineering and Technology, Fifth Settlement, Cairo, EGYPT \\ *Corresponding Author: e-mail: almoatazabdelaziz@hotmail.com, Tel.+20-100-1372930
}

\begin{abstract}
The electrical power systems function as a huge interconnected network dispersed over a large area. A balance exist between generated and consumed power, any disturbance to this balance in the system caused due to change in load as well as faults and their clearance often results in electromechanical oscillations. As a result there is variation in power flow between two areas. This phenomenon is referred as Power Swing. This paper presents a transmission line protection scheme that uses measured values of the currents and voltages of the three phases of two buses (equivalent to PMU data). The measured data is transformed from time domain into phasor domain using Discrete Fourier Transform to predict whether the swing is a stable or an unstable one. The performance of the method has been tested on a simulated system using PSCAD and MATLAB software. The proposed scheme can be used for the detection of out of step condition using equal-area criterion with different types of faults at different locations and different models of transmission lines.
\end{abstract}

Keywords: Phasor Measurement Unit, Global positioning system, Transmission line protection, Power system transient stability, Discrete Fourier Transform, Equal-Area Criterion, Out of step detection.

DOI: http://dx.doi.org/10.4314/ijest.v5i1.1

\section{Introduction}

Transmission line protection is the most elaborate and challenging function in power system protection. About two-thirds of faults in power systems occur on the transmission line network. Consequently, it has received extensive attention from researchers and designers in the area of power system protection (Sachdev, 1997; Electricity, 1995). Today's power systems are interconnected networks of transmission lines linking generators and loads into large integrated systems, some of which span entire countries and even continents (Grigsby, 2007). The main requirements for the reliable operation of such systems are to keep the synchronous generators running in parallel and with adequate capacity to meet the load demand. In power system stability studies the term transient stability usually refers to the ability of the synchronous machines to remain in synchronism during the brief period following a large disturbance, such as a short circuit on a bus (Definition.., August 2004). In large disturbance system nonlinearities play a dominant role. In order to determine transient stability or instability following a large disturbance, or a series of disturbances, time-domain simulation (TDS) method is usually employed to solve the set of nonlinear equations describing the system dynamic. Conclusion about stability or instability can then be drawn from an inspection of the solution (Bettiol, 2003).

In the actual operation of an electric power system, the parameters and loading conditions are quite different from those assumed at the planning stage. As a result, to ensure power system transient stability against possible abnormal conditions due to contingences (disturbances), the system operator needs to simulate contingences in advance, assess the results, and take preventive control action if required. The TDS technique is the most accurate method for assessing the power system transient stability (Kundur, 1994) and (Pavella, 1994). The TDS approach can be applied to any level of detail of power system models and gives visual information about state variables. One of the main disadvantages of the TDS approach, except for being time-consuming, is 
that it does not provide information about the stability margin of the system (Karami, May 2011). The transient energy function method (Pai, 1989; Fouad, 1992) and extended equal-area criterion (Xue, 1989; Xue, 1988) have also been applied in power system transient stability assessment. However, these methods have some modeling limitations and they still need a lot of computations to determine an index for transient stability analysis (Colvara, 2009).

Distance relaying technique has attracted considerable attention for the protection of transmission lines. The principle of this technique is to measure the impedance at a fundamental frequency between the relay location and the fault point, and to determine whether a fault is internal or external to a protection zone based on the measured impedance. Voltage and current data at the relay location are used for this purpose. The measured impedance is affected by power swing, load current, and many other factors. For a double-circuit transmission line, the measured impedance is also affected by the mutual coupling effect caused by the zerosequence current of the adjacent parallel circuit. The erroneous trip decision may have a serious impact on the dynamic stability of power system (IET, 1995).

A major problem in the application of distance relay is associated with double-circuit transmission line distance protection. A general behavior of distance relays applied to double-circuit lines is that they under-reach when the parallel circuit is in service and that they over-reach when the parallel circuit is out of service and earthed at both ends. The inaccuracy caused by the influence of parallel circuit is normally dealt with by applying a safety margin in the protection zone boundary. General guidelines have been developed in order to set the appropriate margin. Typically, $15 \%$ or even more of the line length is covered by the backup zones. These guide- lines assume a general positioning of the line-to-be-protected in a static power system and power system variations are not taken into account. The actual influence of parallel circuits, however, depends on the actual infeed during a fault. Studies show that the characteristics of the entire power system can affect the accuracy of the fault distance calculation. As a result, severe over-reach can occur unexpectedly and affect the selectivity of the protection system (Waiker, 1996; Bhalja, 2005).

The technology of synchronized phasor measurements is well established. It provides an ideal measurement system for monitoring and controlling a power system, especially during stressed conditions. The essential feature of the technique is that it measures positive sequence (and negative and zero sequence quantities, if needed) voltages and currents of a power system in real time with precise time synchronization. This allows accurate comparison of measurements over widely separated locations as well as potential real-time measurement based control actions (Horowitz, 1995) and (Phadke, 1993).A new approach, considering synchronized measurement data from both ends of a transmission line, to protect transmission line is presented in (Zadeha, 2011).

A method based on the well-known Equal-Area Criterion (EAC) using PMU to protect system against loss of synchronism in interconnected systems for three phase short circuit faults for different mechanical loading and different fault clearance time is described in (Bozchalui, 2006). Modification of EAC in $\delta$ domain to time domain, developing an out-of-step detection algorithm based on EAC in time domain which is also referred to as energy equilibrium criterion in time domain for three phase short circuit faults at different locations is described in (Paudyal, 2009).

This paper presents a modification on an existing algorithm in (Berkestedt, 2007), which presents a study for power oscillations with a laboratory model comprising a strong network, a transmission line and a generator, an algorithm tested for only a three phase short circuit fault. A transmission line protection scheme that uses measured values of the currents and voltages of the three phases of two buses (equivalent to PMU data) is presented. The measured data is transformed from time domain into phasor domain using Discrete Fourier Transform to predict whether the swing is a stable or an unstable one. This scheme can be used for the detection of out of step condition using equal-area criterion with different types of faults at different locations and different models of transmission lines.

\section{Phasor Measurement Unit}

The modern PMUs use one pulse per second signals provided by the Global positioning system (GPS) satellite receivers. GPS system consists of 24 satellites in six orbits at an approximate altitude of 10,000 miles above the surface of the earth. The accuracy of the GPS timing pulse is better than $1 \mu \mathrm{s}$, which for a $50 \mathrm{~Hz}$ system corresponds to about 0.018 degrees, this accuracy is more than enough to ensure that the measurements obtained by such clocks will be simultaneous for the purpose of estimation and analysis of the power system state (Phadke, 2006). The main advantage of PMU is that measured values have same time reference. PMU uses GPS signals to time synchronizing and after calculating voltage and current phasors, using Discrete Fourier Transform (DFT), PMU adds a time tag to sampled data and synchronize them with GPS signals (Bozchalui, 2006).

\subsection{Measurements Techniques}

The basic definition of the phasor representation of a sinusoid is illustrated in Figure 1. Assume a single frequency constant sinusoid of frequency $\omega$ is observed starting at time $t=0$. The sinusoid can be represented by a complex number called 'Phasor' which has a magnitude equal to the root-mean-square (rms) value of the sinusoid, and whose angle is equal to the angle between the peak of the sinusoid and the $t=0$ axis. 

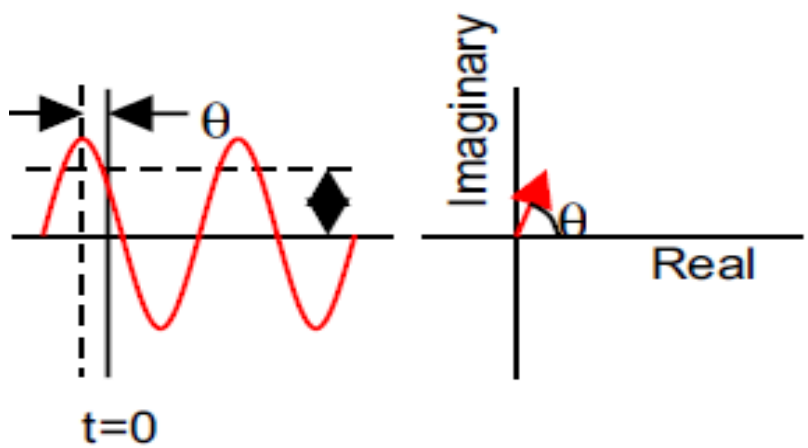

Figure 1: Definition of a Phasor, a complex number representation of a constant pure sinusoid.

If the sinusoid is not a pure sine wave, the phasor is assumed to represent its fundamental frequency component calculated over the data window.

The most common technique for determining the phasor representation of an input signal is to use data samples taken from the waveform, and apply the discrete Fourier transform (DFT) (Ree, 2010) as shown in Figure 2. The sampling clocks are usually kept at a constant frequency even though the input signal frequency may vary by a small amount around its nominal value as described in (Phadke, 1991).

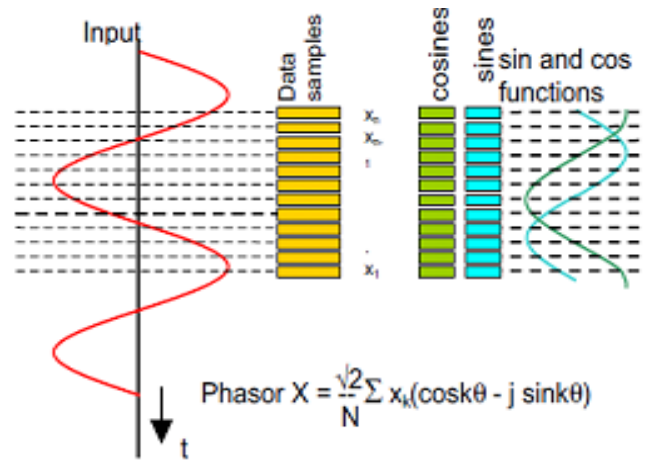

Figure 2: Estimation of phasors from sampled data using Discrete Fourier Transform.

A more computationally efficient method is to compute the estimated phasor recursively by adding the contribution made by the new sample, and subtracting the contribution made by the oldest sample. This is illustrated in Figure 3. A useful artifact of the recursive DFT algorithm is that the constant sinusoid of nominal frequency produces a constant phasor (Phadke, 2006).

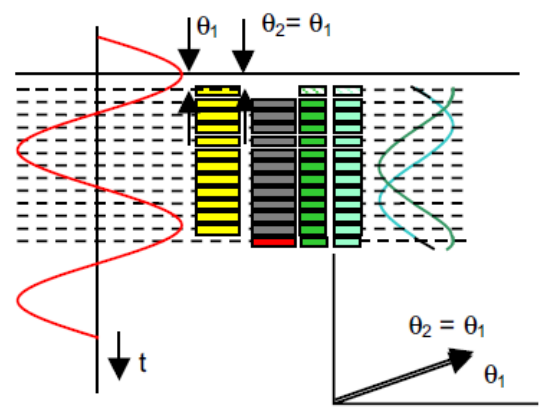

Figure 3: Recursive estimation of phasors from sampled data with moving window DFT.

A phase may be used as an indicator of the dynamic performance of a power system (Benmouyal, 2002).

\section{Applications of PMUs in Power System}

The synchronized phasor measurement technology is relatively new, and consequently several research groups around the world are actively developing applications of this technology. It seems clear that many of these applications can be conveniently grouped as follows: 


\subsection{Advanced network protection}

This category of applications of synchronized phasor measurements is that of enhancing the effectiveness of power system protection. This involves equipment and system protection, as well as remedial action schemes. An example of phasor measurements used for protection is given in the adaptive out-of-step relaying study, using concepts from transient stability analysis; it is possible to design improved out-of-step relays (Hart, 2001).

\subsection{Detection of Instability}

Detection of instability in power systems is not a relaying function. However, many relaying functions (load shedding, for example) depend upon the premise that given the current state of a power system, it will remain stable following a transient oscillation. Conversely, the out-of-step tripping function is based upon, the premise that the post-disturbance system will be unstable. In a power system consisting of two synchronous machines and a connecting network over which synchronizing power can flow, the problem of instability detection can be solved in real-time. The equal-area criterion is applicable in this case, and if the machine rotor angles and speeds can be measured in real-time a prediction algorithm can be developed for the detection of instability (Thorp, 1988).

\subsubsection{Phase as Indicator of the Dynamic Performance of a Power System}

Synchronous machines must adapt to different operating conditions when exchanging real power across a power system (Stevenson, 1986).The machines accelerate or decelerate to adapt to changing power transfer requirements that occur during system disturbances. Power system dynamics involve the electrical properties, as well as the mechanical properties, of all the electrical machines in the system. For the purpose of this discussion, assume a two-pole synchronous machine where the mechanical and electrical degrees are equal.

The difference between shaft torque $T_{m}$ and electromechanical torque $T_{e}$, in a machine determines the accelerating torque $T_{a}$, as shown by Equation (1). In generators $\mathrm{T}_{\mathrm{a}}>0$ accelerates the machine.

$T_{a}=T_{m}-T_{e}$

We can represent power $\mathrm{P}$ as a function of torque $\mathrm{T}$ according to Equation (2).

$P=T * \omega$

Where,

$\mathrm{T}$ is the torque, N.m

$\omega$ is the angular velocity, $\mathrm{rad} / \mathrm{s}$

It can be seen from Equation (3) that the change of the angular rotor position $\theta$ with respect to time determines the angular velocity $\omega$.

$\omega=\frac{d \theta}{d t}$

The torque $\mathrm{T}$ is a function of the moment of inertia $\mathrm{J}$ and the angular acceleration $\alpha$ according to Equation (4).

$T=J * \alpha$

Where,

$\mathrm{J}$ is the moment of inertia, $\mathrm{kg} \cdot \mathrm{m}^{2}$

$\alpha$ is the change of the angular velocity with respect to time, $\mathrm{rad} / \mathrm{s}^{2}$

As in Equation (5), the angular momentum $\mathrm{M}$ is a function of the moment of inertia $\mathrm{J}$ and the angular velocity $\omega$.

$M=J * \omega$

With equation (6), we can represent the accelerating power $\mathrm{P}_{\mathrm{a}}$ as a function of the angular acceleration $\alpha$ and as a function of the angular rotor position $\theta$.

$P_{a}=T_{a} * \omega=M * \alpha=M * \frac{d^{2} \theta}{d t^{2}}$

The rotor angle position can be expressed with respect to a synchronous reference frame that rotates at synchronous speed $\omega_{\text {syn }}$. The angular rotor position $\theta$, is equal to the phase angle due to the synchronous rotating reference $\omega_{\text {syn }} *_{t}$ plus the angular displacement from the synchronous rotating reference $\delta$ as shown in Equation (7). 
$\theta(t)=\omega_{\text {syn }} * t+\delta$

The angular velocity $\omega$ is:

$\omega=\frac{d \theta}{d t}=\omega_{\text {syn }}+\frac{d \delta}{d t}$

Taking the derivative of the angular velocity, we can rewrite Equation (6) as a function of $\delta$ :

$P_{a}=M \frac{d^{2} \delta}{d t^{2}}$

We can express Equation (9) as a function of the constant inertia $\mathrm{H}$ with power expressed in per unit as follows:

$P_{a}=P_{m}-P_{e}=\frac{2 H}{\omega_{s y n}} * \frac{d \omega}{d t}$

Where,

$\mathrm{P}_{\mathrm{m}}$ is the mechanical power supplied to the generator, $\mathrm{pu}$

$\mathrm{P}_{\mathrm{e}}$ is the electrical power supplied to the system, pu

$\mathrm{H}$ is the constant of inertia, sec

Equation (10) is known as the swing equation; one swing equation per machine is necessary to model the network dynamics. When the load-generation equation is balanced (total load equals total generation), machine speeds are practically equal to synchronous speed. The angular displacements, $\delta$, of machines in a system provide information about the system dynamics. One cannot measure this angular displacement mechanically. By computing the voltage phasor behind the machine transient reactance, one can study the phase angle variations to obtain an image of the machine angular displacement. In practice, machine-oscillating modes can be determined by measuring the phase angle of the positive-sequence voltage phasor at the machine terminals (Benmouyal, 2002).

\subsubsection{Adaptive Out-Of-Step Protection}

It is recognized that a group of generators going out of step with the rest of the power system is often a precursor of a complete system collapse. Whether an electromechanical transient will lead to stable or unstable condition has to be determined reliably before appropriate control action could be taken to bring the power system to a viable steady state. Out-of-step relays are designed to perform this detection and also to take appropriate tripping and blocking decisions (Ree, 2010). For single machine system or two machines system, EAC is an effective method to assess power system stability. EAC has excellent characteristic, it inspires many scholars to apply EAC to multi-machines (Fang, 2009). To multi-machines system, all generator pairs must synchronous if whole system is stable; and a generator pair must asynchronous firstly if whole system is unstable, and vice versa. It means whole system stability assessment is equal to a special generator pair stability assessment. EAC may be applied to the generator pair through a new way (Fang, 2009).

\section{Theory of Single Machine-Infinite Bus System}

\subsection{Power Transfer Equation}

For a simple lossless transmission line connecting a generator and infinite bus as shown in Figure 4.

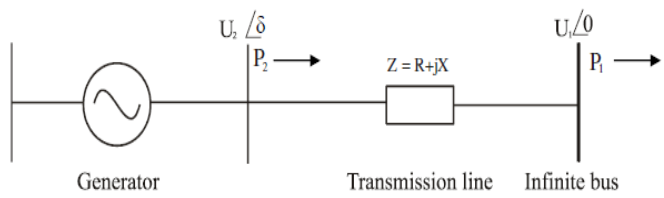

Figure 4: One machine against infinite bus diagram.

If $\mathrm{V}_{1}=U 1, \mathrm{~V} 2=U 2 \cos \delta+\mathrm{j} U 2 \sin \delta$,

$\mathrm{Z}=\mathrm{R}+\mathrm{j} \mathrm{X}$

It is well known that the active power P transferred between two generators for a lossless line can be expressed as:

$P=|\mathrm{U} 1| * \frac{|\mathrm{U} 2|}{X} * \sin \delta$

Where,

$\mathrm{V}_{1}$ is the voltage of the infinite bus (reference voltage), volt

$\mathrm{V}_{2}$ is the voltage of the generator bus, volt 
$\delta$ is the angle difference between the generator and infinite bus, rad

$\mathrm{X}$ is the total reactance of the transmission line and generator, ohm

The impedance is reduced to the reactance of the line because the resistance is often small and gives little contribution to the solution, the maximum amount of power that can be transferred over the line $\mathrm{P}_{\max }$ when $\delta=90$ degree (Berkestedt, 2007).

4.2 The Power Angle Curve

The generator in Figure 4 is in stable operation at a phase angle of $\delta$ compared to the infinite bus, i.e. the voltage at the generator bus $\mathrm{U} 2$ is leading the voltage at the infinite bus $\mathrm{U} 1$ by an angle $\delta$. The mechanical power input Pm and the electrical power output $\mathrm{P}_{\mathrm{e}}$ drawn in Figure 5 describes the power balance of the generator. The curves intersect at two points, the stable equilibrium point and the unstable equilibrium point.

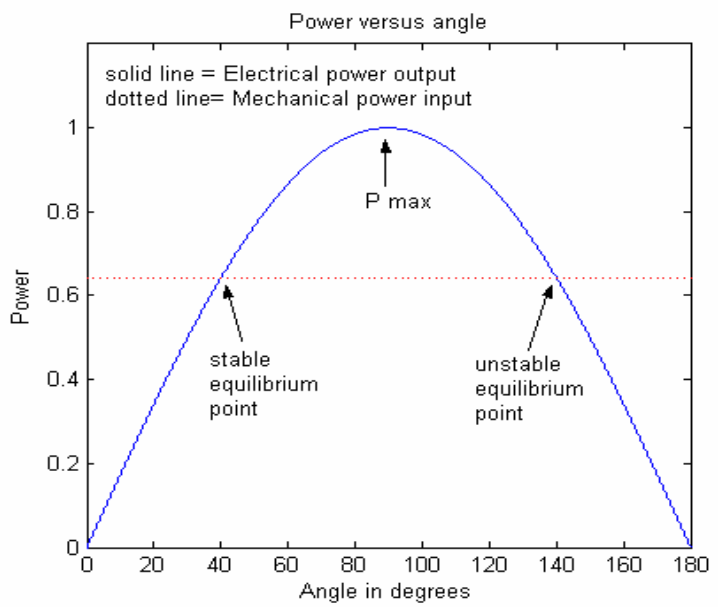

Figure 5: Input (dashed) and Output (solid) power of turbine generator.

4.3 Transiently Stable and Unstable Systems

In Figure 6 the changes of angle and power transfer between the generator and the infinite bus before, during and after a fault are plotted.

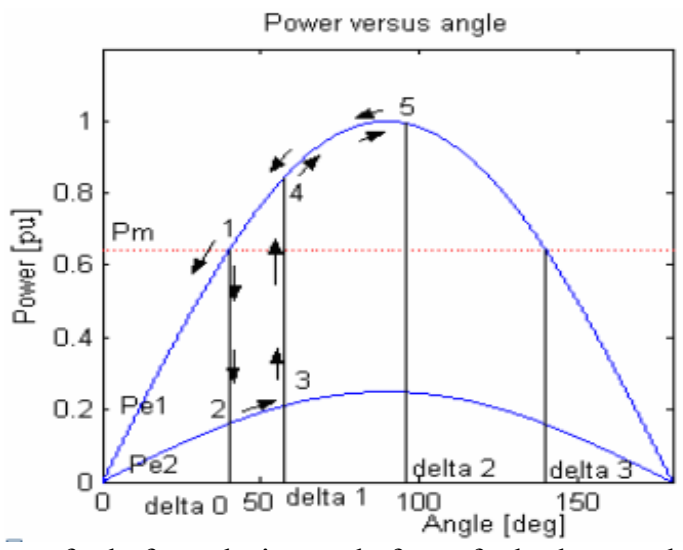

Figure 6: Power transfer before, during and after a fault close to the turbine-generator.

1. Before the fault, at steady-state condition, the system operates at the stable equilibrium point at angle delta0.

2. When a fault occurs, the electrical power output gets an instantaneous decrease and becomes much smaller than the mechanical power.

3. During the fault the angle delta will increase from delta0 to delta1. The rotor angle is gaining velocity and starts to accelerate in the right direction during the fault. When the fault is cleared, at point 3, the impedance between the machine and infinite bus will change again. The change leads to an increased level of the electrical power output.

4. If it is assumed that the system goes back to its pre-fault conditions the electrical output power will jump from point 3 to point 4 . The angle delta1 will remain the same. During the time when the electrical power output was lower than the mechanical power input the generator gained energy.

5. The energy gained has to be transferred into the system, before a stable equilibrium point can be reached again. Therefore the rotor angle is still increasing, but it has started to decelerate. Point 5 is reached when all the power gained during the fault is transferred into the system and find a new stable equilibrium point (Berkestedt, 2007). 


\subsection{The Equal-Area Criterion}

The equal-area criterion can be used to calculate the maximum fault clearing time before the generator loses synchronism. The equal-area criterion integrates the energy gained when the turbine-generator is accelerating, during the fault (area A, in Figure 7) and compares that area with the decelerating area, (area B, in Figure 7) when the generator exports the energy stored during the fault.

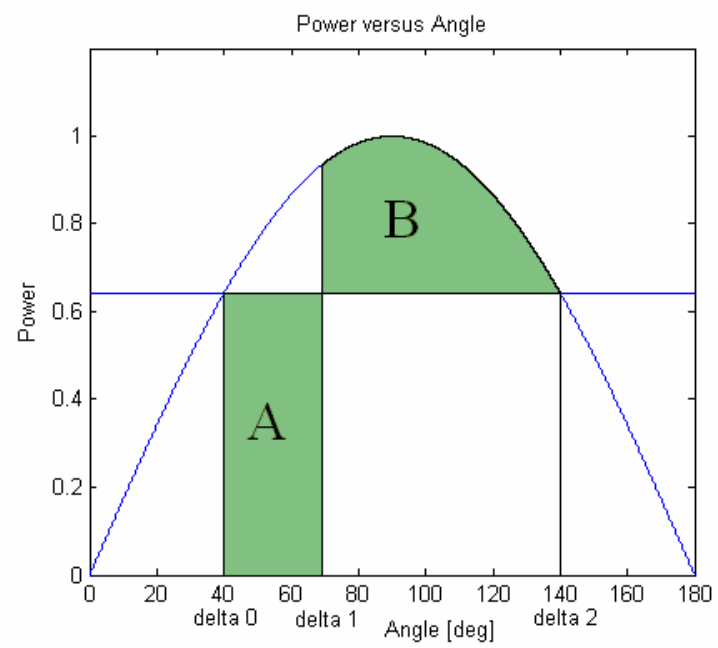

Figure 7: Equal-area criterion with an acceleration area A and a decelerating area B (Berkestedt, 2007).

Area $\mathbf{A}$ represents the total kinetic energy gained during the acceleration period. As soon as the fault is cleared at angle $\boldsymbol{\delta} \mathbf{1}$ the angle will continue to increase and the kinetic energy gained during the fault period will expand into the power system, when area $\mathbf{B}$ is equal to area $\mathbf{A}$ angle $\boldsymbol{\delta}$ has reached its maximum value (Berkestedt, 2007).

$$
\begin{aligned}
& A=\int_{\delta_{o}}^{\delta_{1}}\left(P_{m}-P_{e, \text { fault }} \sin \delta\right) d \delta \\
& B=\int_{\delta_{1}}^{\delta_{2}}\left(P_{e, \text { max }} \sin \delta-P_{m}\right) d \delta
\end{aligned}
$$

When area $\mathbf{A}<\mathbf{B}$ the system will be stable and if $\mathbf{A}>\mathbf{B}$ the system will be unstable.

\section{Evaluation of the proposed protection scheme}

\subsection{Power system model}

The model describes a hydro power plant at Harsprånget with a transformer and a high voltage transmission line .One end of the transmission line can be connected to the rest of the Swedish network. The model in the lab can be described as one machine against an infinite bus (Berkestedt, 2007). Using the Electromagnetic Transient program PSCAD/EMTDC, a single machine threephase $400 \mathrm{kV}$ power system against infinite bus with a line of $900 \mathrm{~km}$ length divided into six identical $\pi$ sections each of length $150 \mathrm{~km}$ has been simulated for the analysis of the proposed protection scheme. The one-line diagram of the studied system is shown in Figure 8 and its parameters are shown in Table 1.

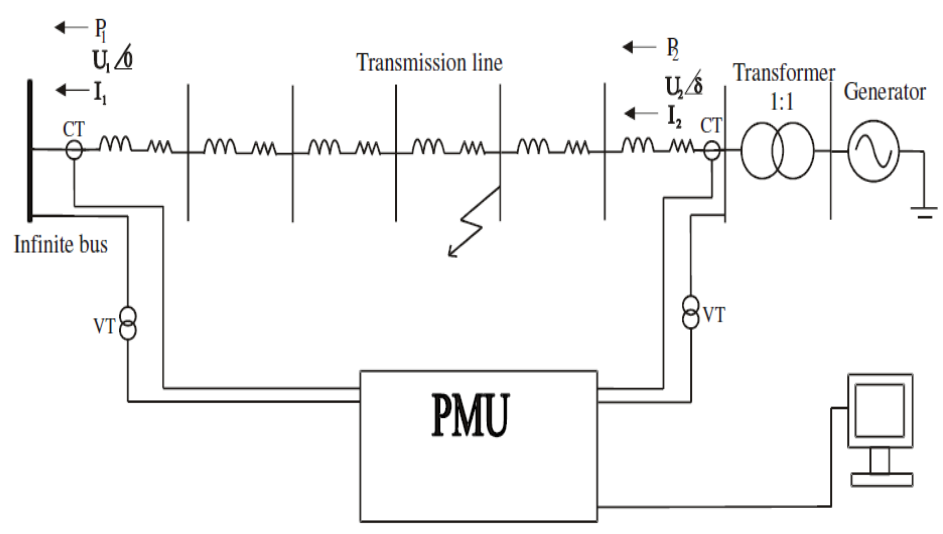

Figure 8: Simulated power system model (Berkestedt, 2007). 
The transmission line is a double-circuit line and simulated using both the Bergeron model and the frequency-dependent model options (two available models in PSCAD/EMTDC, the first is a very simple model and the second is the most advanced time domain model and it is useful wherever the transient behavior of the line or cable is important).

Table 1: Simulated power system parameters

\begin{tabular}{|l|l|}
\hline Positive sequence resistance $\mathrm{R}$ & $2.925^{*} 10^{\wedge}-9 \mathrm{p} . \mathrm{u} / \mathrm{m}$ \\
\hline Positive sequence inductive reactance $\mathrm{X}_{\mathrm{L}}$ & $3.6225^{*} 10^{\wedge}-8 \mathrm{p} . \mathrm{u} / \mathrm{m}$ \\
\hline Positive sequence capacitive reactance $\mathrm{X}_{\mathrm{C}}$ & $0.571^{*} 10^{\wedge} 6 \mathrm{p} . \mathrm{u} / \mathrm{m}$ \\
\hline Zero sequence resistance $\mathrm{R}$ & $8.775^{*} 10^{\wedge}-9 \mathrm{p} . \mathrm{u} / \mathrm{m}$ \\
\hline Zero sequence inductive reactance $\mathrm{X}_{\mathrm{L}}$ & $1.08675^{*} 10^{\wedge}-7 \mathrm{p} . \mathrm{u} / \mathrm{m}$ \\
\hline Zero sequence capacitive reactance $\mathrm{X}_{\mathrm{C}}$ & $0.793^{*} 10^{\wedge} 6 \mathrm{p} . \mathrm{u} / \mathrm{m}$ \\
\hline
\end{tabular}

The performance of the proposed MATLAB program has been tested for different faults in a validation set with different fault types and fault locations.

\subsection{Out of Step Detection Algorithm}

Figure 9 shows a flow chart for the proposed out-of-step detection algorithm. First the algorithm takes data from the EMTDC/PSCAD program at different time steps which is the same as the sample interval for the PMU, 0.02 seconds. This data will be converted by a DFT to complex phasors of voltages and currents. The algorithm takes complex current and voltage. From these vectors it calculates new vectors with impedance, phase angle and power for all time steps. After that the program determines the areas A and B and finally checks if there is out-of-step condition or not.

\section{Explanation of the steps of the algorithm is as follows:}

1- The data taken from PSCAD/EMTDC (equivalent to PMU data) will be saved in a MATLAB program. These data will be transformed from time domain to phasor domain by DFT.

2- At $\mathrm{t}=0$, first line of data, it is assumed to have a stable values (stable angle and mechanical input power are calculated).

3 - Angle and power are calculated at each time step $\Delta \mathrm{t}=0.02 \mathrm{sec}$.

4- IF statement for change in angle.

A difference larger than the threshold value will operate the power swing algorithm, the threshold value is taken from studying the graphs of the change of phase angle.

5- IF statement for change in angle and value of electric power output.

If the angle has changed too much and the electric power output has decreased to a level below the mechanical power input, the system will experience a power swing, and the algorithm will calculate area $\mathbf{A}$ and area $\mathbf{B}$.

If these changes in angle and electric power output don't occur, the algorithm tells that there will be a disruption but the system will stay synchronized.

6- Warning message that the system has had a failure but will not lose synchronism.

7- Calculation of areas $\mathbf{A}$ and $\mathrm{B}$.

8- IF statement to compare between areas A and B.

As long as area A is smaller than area B, the algorithm will continue, and if area $\mathbf{A}$ is larger than area B, the algorithm will stop and sends out a warning Out of Step condition.

9- A warning message, the system will lose synchronism (Out of Step Condition).

\subsection{Simulation Results}

Different types of faults are applied to the system in the transmission line near to the generator bus, as a fault at a bus near the infinite bus will cause very high fault current and will not be possible to measure. Some test results are presented in the following subsections.

5.3.1 Case 1: 3-phase short circuit at $300 \mathrm{~km}$ from generator side using Bergeron Model

Time of fault: $0.4 \mathrm{sec}$.

Duration of fault: $0.05 \mathrm{sec}$.

Transmission line: Bergeron model options, manual entry of admittance $\mathrm{Y}$, impedance $\mathrm{Z}$.

Figures 10, 11, 12 and 13 show voltage and current waveforms at both sides (generator bus and infinite bus) obtained from the simulation using the PSCAD/EMTDC program. 


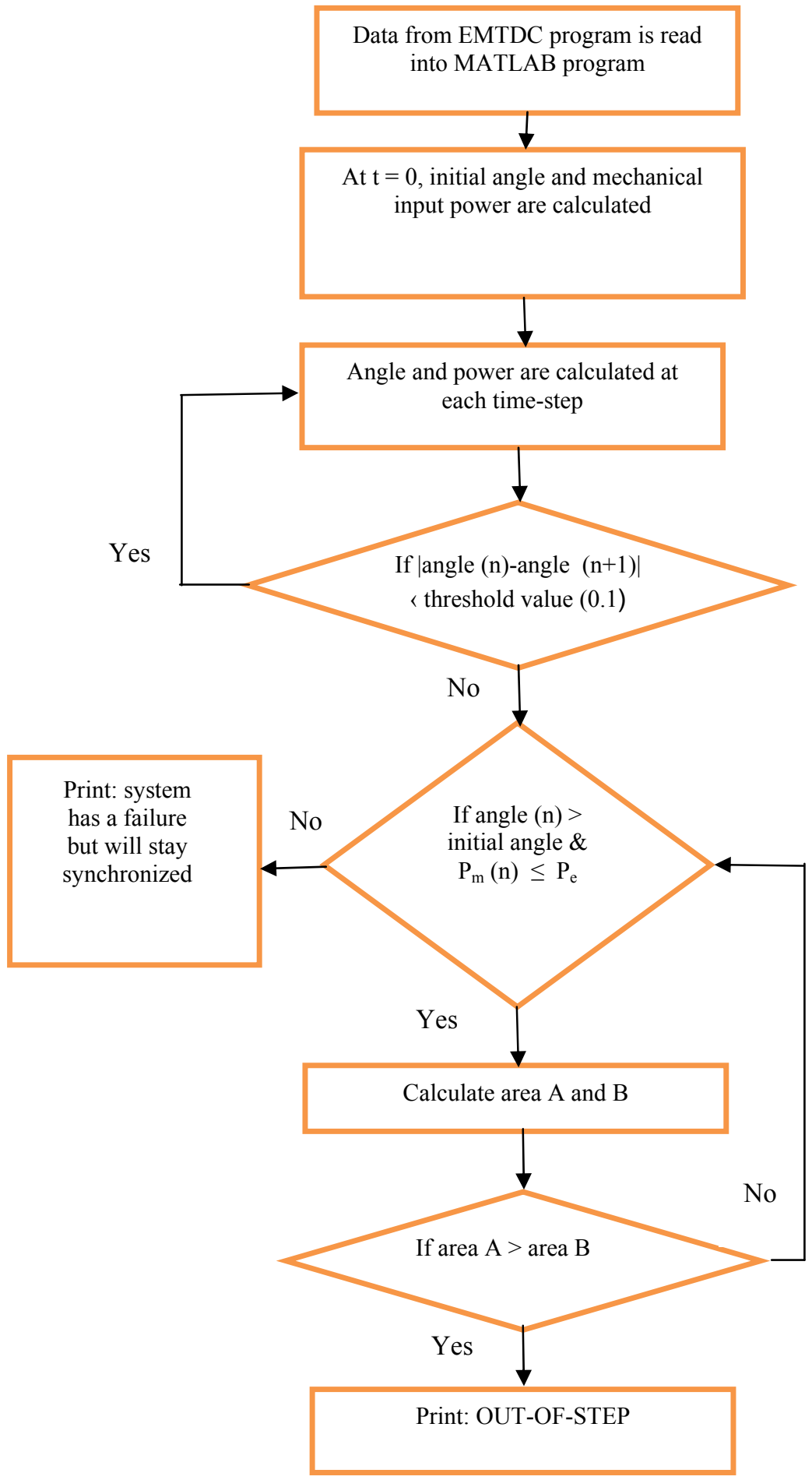

Figure 9: Flowchart of algorithm 


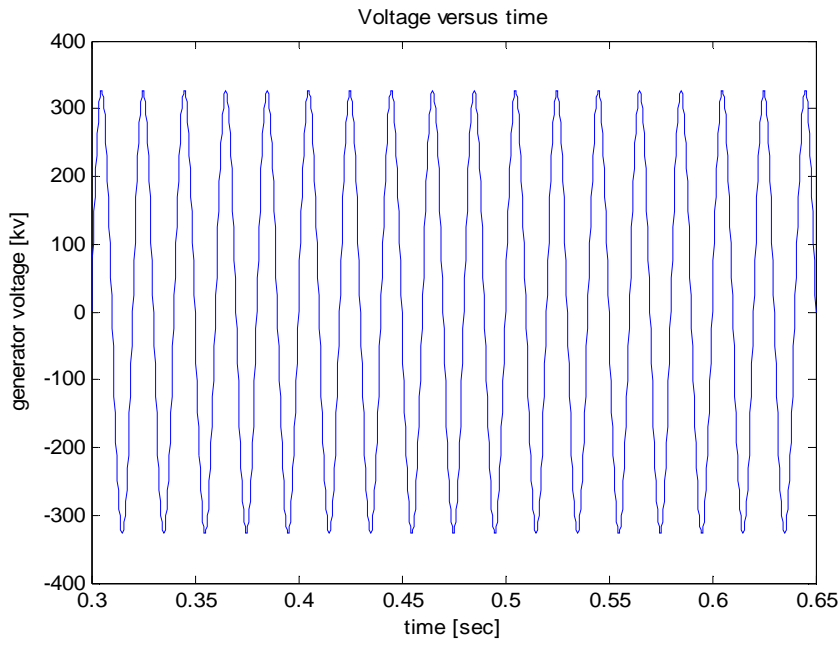

Figure 10: voltage at generator bus.

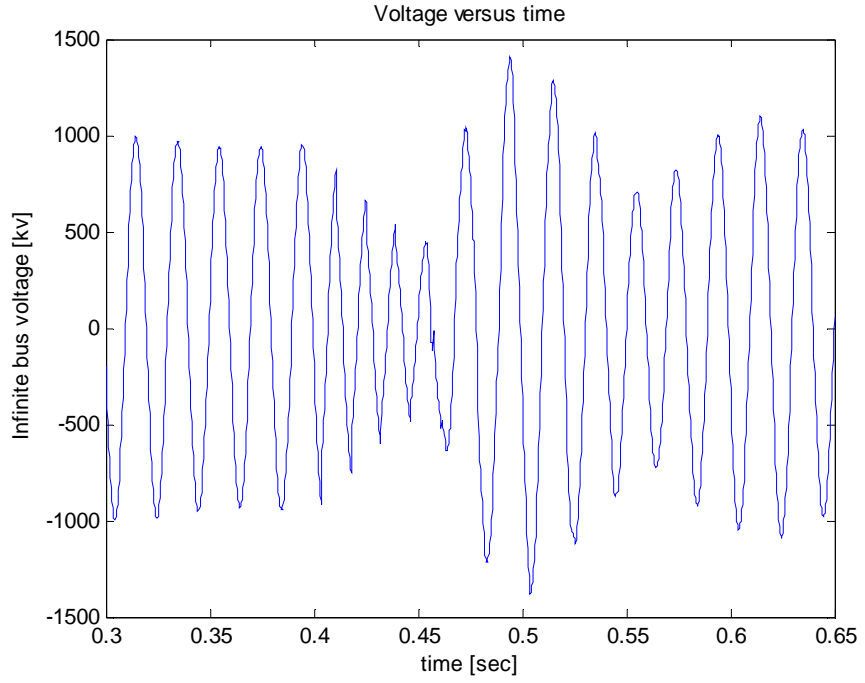

Figure 11: voltage at infinite bus.

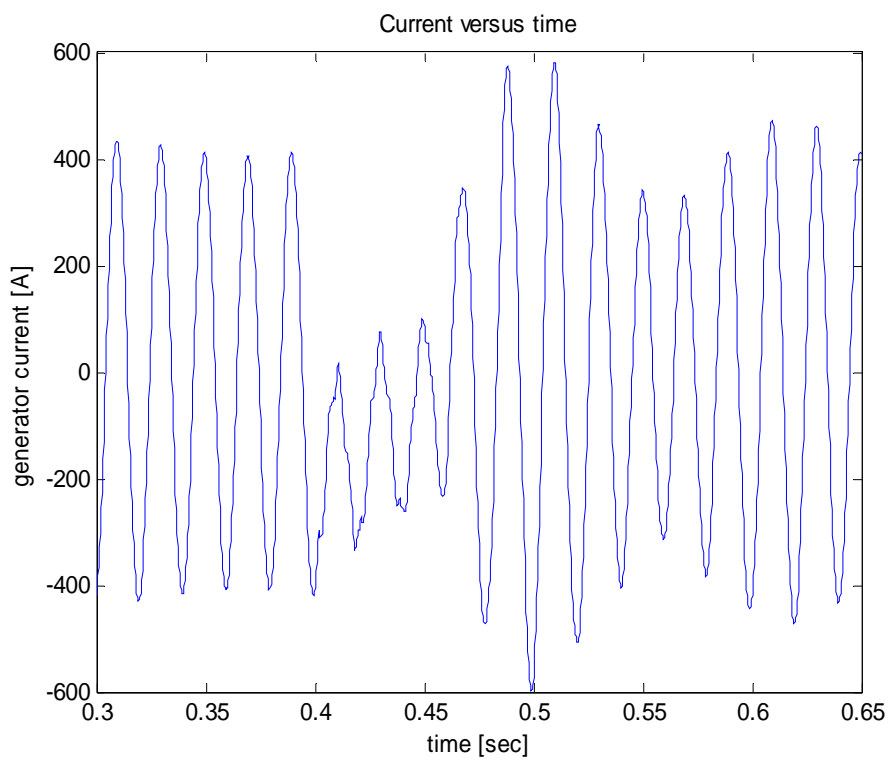

Figure 12: current at generator bus. 


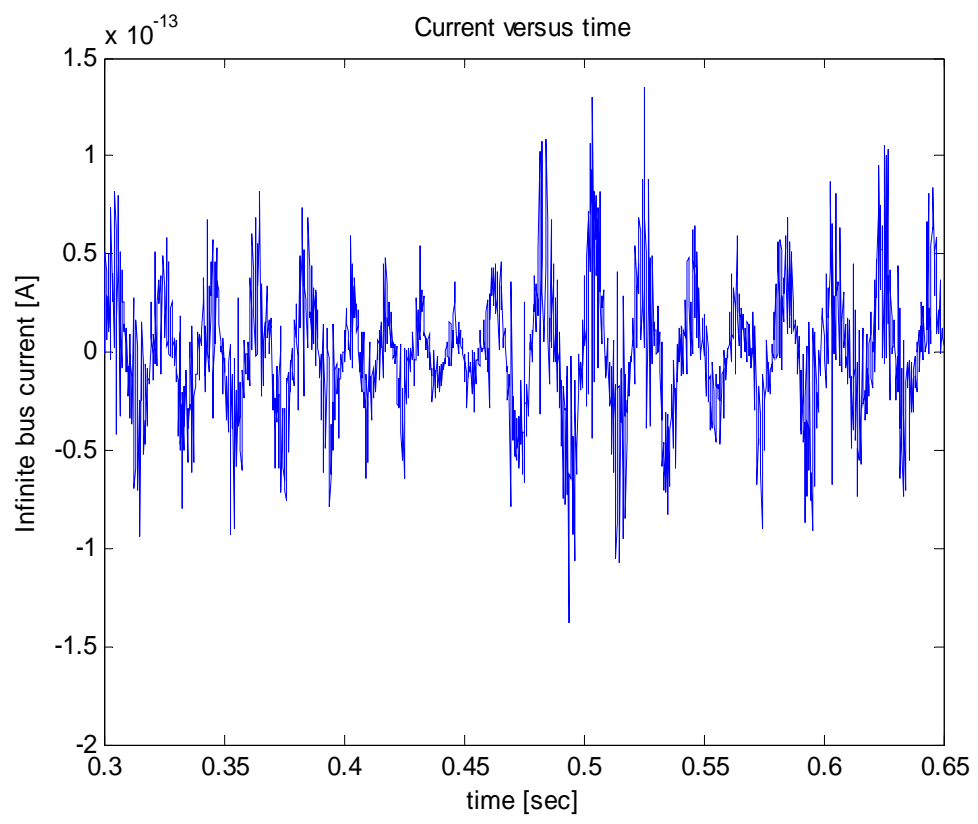

Figure 13: current at infinite bus.

The proposed scheme is tested for calculating areas A and B for this fault and determines if the generator will be out of step (unstable condition), this fault tested by TDS and the rotor angle will increase directly with time and this is a detection for unstable condition as shown in Figure 14.

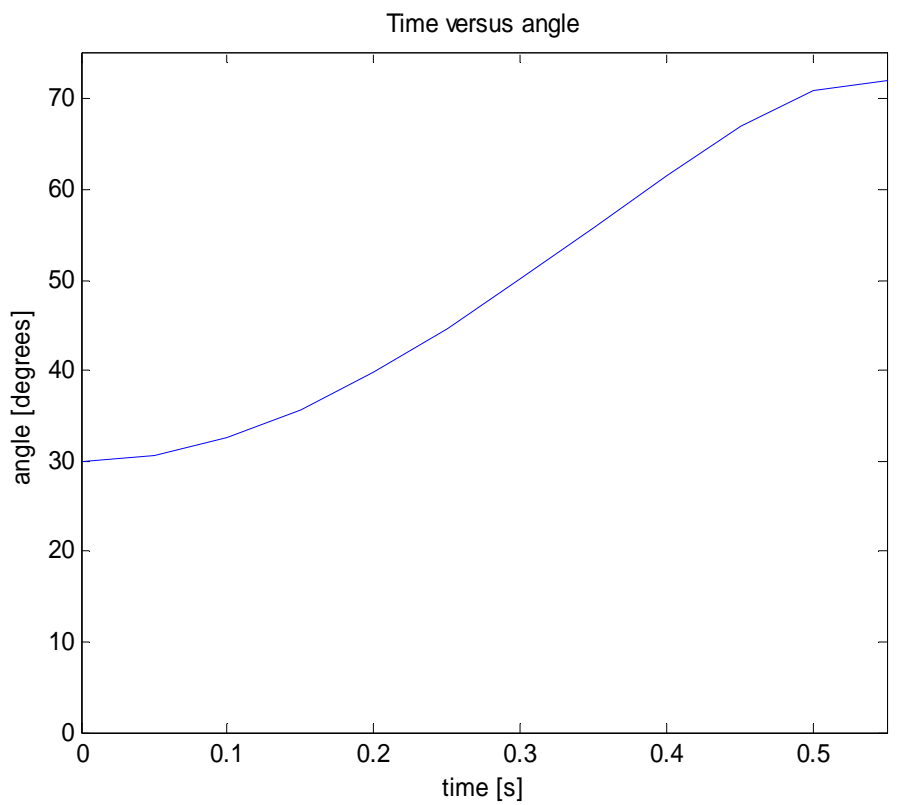

Figure 14: rotor angle against time for an unstable case.

\subsubsection{Case 2: 3-phase short circuit at $300 \mathrm{~km}$ from generator side using frequency-dependent model}

Time of fault: $0.3 \mathrm{sec}$.

Duration of fault: $0.15 \mathrm{sec}$.

Transmission line: frequency-dependent model.

Figures 15, 16, 17 and 18 show voltage and current waveforms at both sides (generator bus and infinite bus) obtained from the simulation using the PSCAD/EMTDC program. 


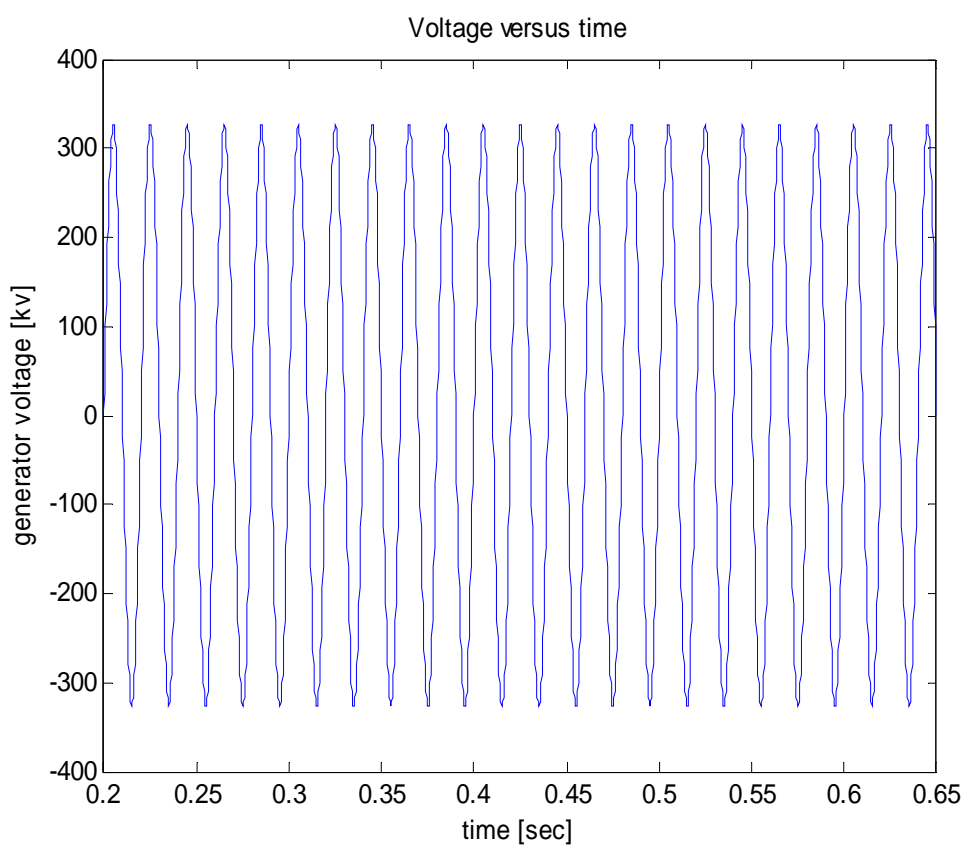

Figure 15: voltage at generator bus.

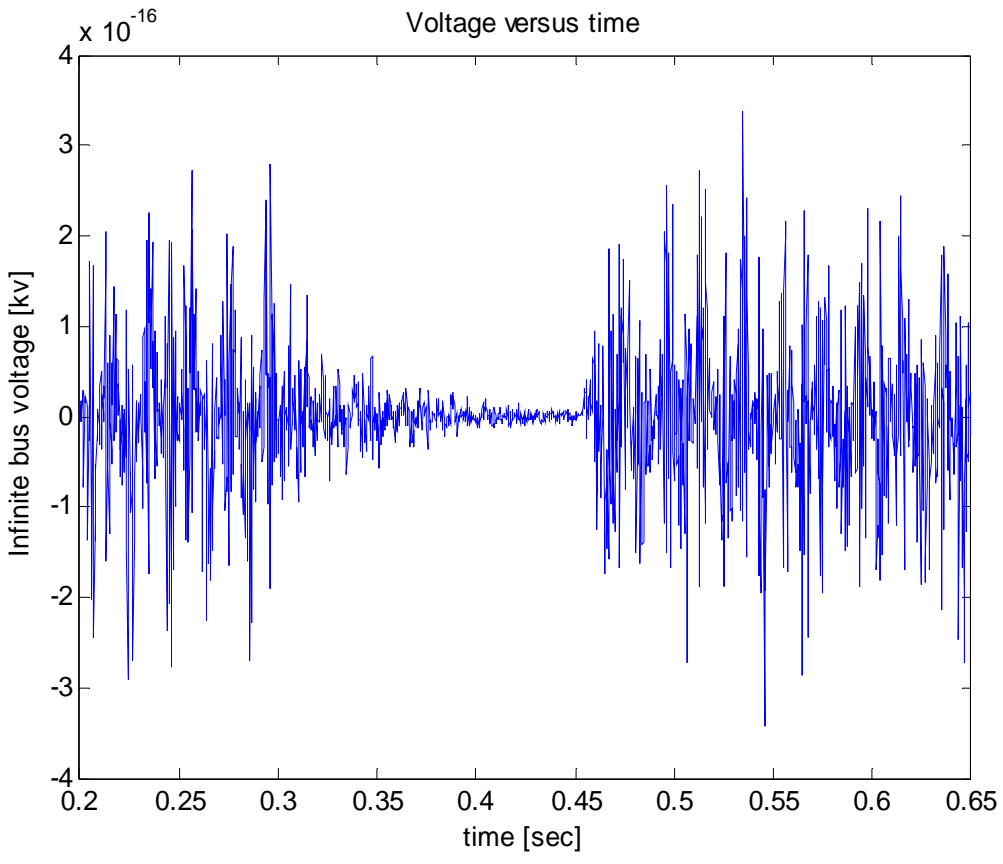

Figure 16: voltage at infinite bus. 


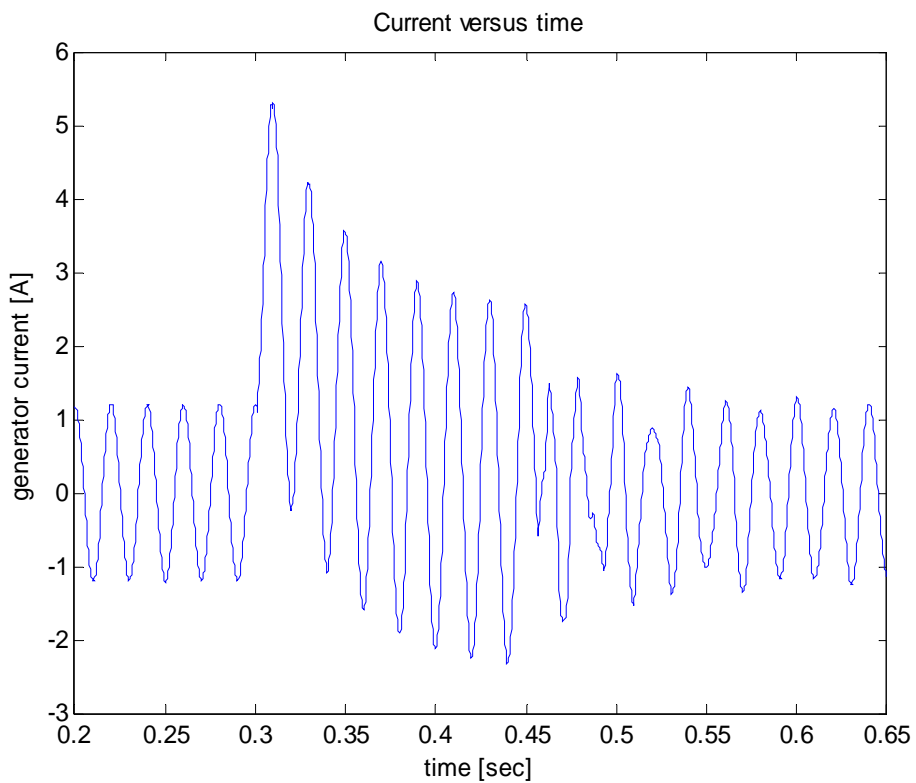

Figure 17: current at generator bus.

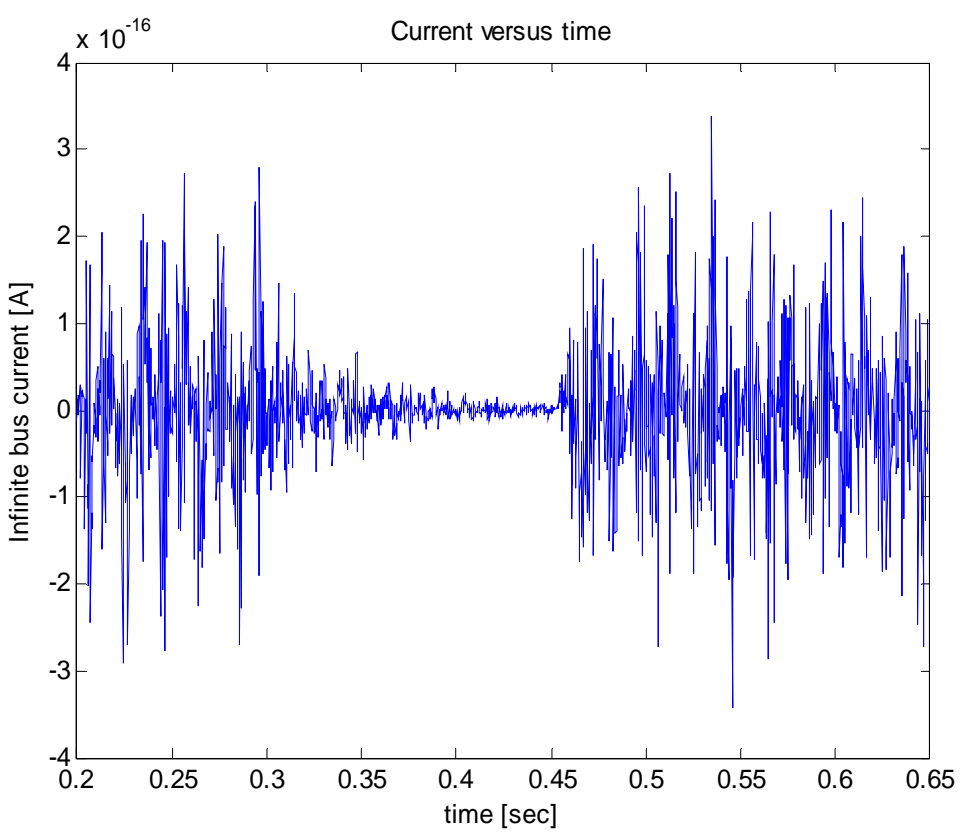

Figure 18: current at infinite bus.

The proposed scheme is tested for calculating areas A and B for this fault and determines if the system has had a failure but will not lose a synchronism (stable condition), this fault tested by TDS and the rotor angle will increase directly with time and then decrease to gain a new stable equilibrium point and this is a detection for a stable condition as shown in Figure 19. 


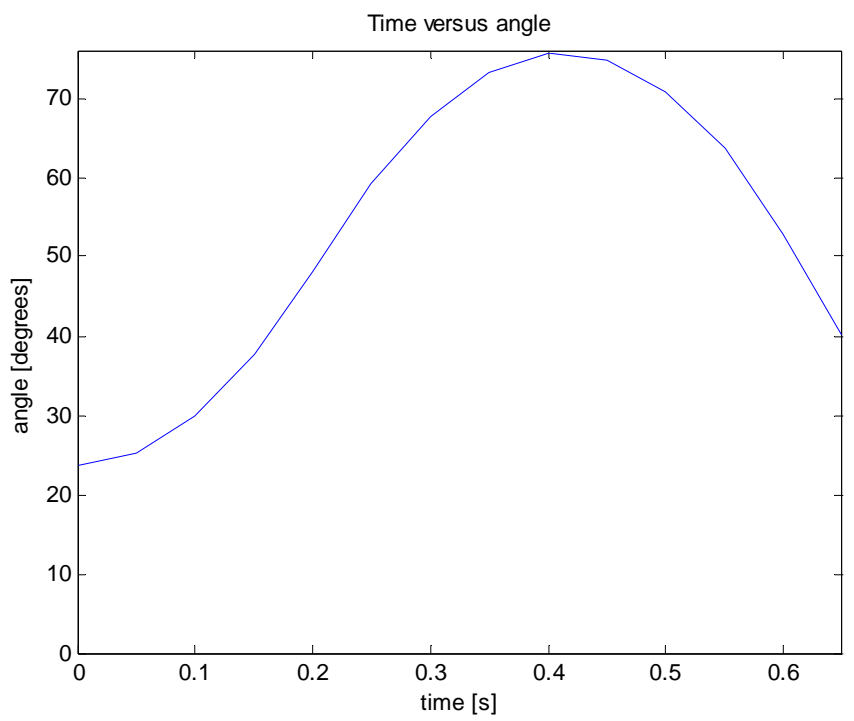

Figure 19: rotor angle against time for a stable case.

\subsubsection{Scheme responses to different faults}

The proposed scheme is tested for detecting the system stability; the program output for different faults at different locations with different models of transmission line is shown in Table 2. Also the effect of variation of the fault inception time and duration for a fault occurring at a certain distance is given in Table 3. It is concluded from Table 2 that the time of fault inception is directly related to the angle difference between the generator and infinite bus $(\delta)$ which will affect the accelerating and decelerating area affecting the stability of the system. Also faults near the infinite bus will cause very high fault currents which will cause instability; for the same values of fault inception time and duration, faults at lengths $600 \mathrm{~km}$ and $750 \mathrm{~km}$ will cause instability while faults at 150,300 and $450 \mathrm{~km}$ are stable. For the three phase short circuit faults, the results obtained by the proposed scheme are compared with the actual values found by the step-by-step method and other cases are compared by TDS and give identical results.

Table 2: Test results of the proposed scheme to different faults at different locations of the transmission line

\begin{tabular}{|l|l|l|l|l|l|}
\hline Fault location & Fault type & $\mathrm{t}_{\mathrm{f}}$ & $\mathrm{D}_{\mathrm{f}}$ & $\begin{array}{l}\text { Proposed Scheme } \\
\text { Output }\end{array}$ & $\begin{array}{l}\text { Time Domain } \\
\text { Simulation }\end{array}$ \\
\hline $150 \mathrm{~km}$ & AG & 0.2 & 0.05 & Stable & Stable \\
\hline $150 \mathrm{~km}$ & AG & 0.3 & 0.05 & Unstable & Unstable \\
\hline $150 \mathrm{~km}$ & BG & 0.3 & 0.05 & Unstable & Unstable \\
\hline $150 \mathrm{~km}$ & CG & 0.3 & 0.05 & Unstable & Unstable \\
\hline $150 \mathrm{~km}$ & BC & 0.2 & 0.05 & Stable & Stable \\
\hline $150 \mathrm{~km}$ & AB & 0.3 & 0.1 & Unstable & Unstable \\
\hline $150 \mathrm{~km}$ & BC & 0.3 & 0.1 & Unstable & Unstable \\
\hline $150 \mathrm{~km}$ & CA & 0.3 & 0.1 & Unstable & Unstable \\
\hline $150 \mathrm{~km}$ & CAG & 0.2 & 0.05 & Stable & Stable \\
\hline $150 \mathrm{~km}$ & ABG & 0.4 & 0.05 & Unstable & Unstable \\
\hline $150 \mathrm{~km}$ & BCG & 0.4 & 0.05 & Unstable & Unstable \\
\hline $150 \mathrm{~km}$ & CAG & 0.4 & 0.05 & Unstable & Unstable \\
\hline $150 \mathrm{~km}$ & ABCG & 0.3 & 0.05 & Unstable & Unstable \\
\hline $300 \mathrm{~km}$ & AG & 0.2 & 0.05 & Stable & Stable \\
\hline $300 \mathrm{~km}$ & AG & 0.3 & 0.05 & Unstable & Unstable \\
\hline $300 \mathrm{~km}$ & BG & 0.3 & 0.05 & Unstable & Unstable \\
\hline $300 \mathrm{~km}$ & CG & 0.3 & 0.05 & Unstable & Unstable \\
\hline $300 \mathrm{~km}$ & BC & 0.2 & 0.05 & Stable & Stable \\
\hline $300 \mathrm{~km}$ & AB & 0.3 & 0.1 & Unstable & Unstable \\
\hline $300 \mathrm{~km}$ & BC & 0.3 & 0.1 & Unstable & Unstable \\
\hline $300 \mathrm{~km}$ & CA & 0.3 & 0.1 & Unstable & Unstable \\
\hline $300 \mathrm{~km}$ & CAG & 0.2 & 0.05 & Stable & Stable \\
\hline $300 \mathrm{~km}$ & ABG & 0.4 & 0.05 & Unstable & Unstable \\
\hline
\end{tabular}


Table 2 (cont'd): Test results of the proposed scheme to different faults at different locations of the transmission line

\begin{tabular}{|l|l|l|l|l|l|}
\hline Fault location & Fault type & $\mathrm{t}_{\mathrm{f}}$ & $\mathrm{D}_{\mathrm{f}}$ & $\begin{array}{l}\text { Proposed Scheme } \\
\text { Output }\end{array}$ & $\begin{array}{l}\text { Time Domain } \\
\text { Simulation }\end{array}$ \\
\hline $300 \mathrm{~km}$ & BCG & 0.4 & 0.05 & Unstable & Unstable \\
\hline $300 \mathrm{~km}$ & CAG & 0.4 & 0.05 & Unstable & Unstable \\
\hline $300 \mathrm{~km}$ & ABCG & 0.3 & 0.05 & Unstable & Unstable \\
\hline $450 \mathrm{~km}$ & AG & 0.2 & 0.05 & Stable & Stable \\
\hline $450 \mathrm{~km}$ & AG & 0.3 & 0.05 & Unstable & Unstable \\
\hline $450 \mathrm{~km}$ & BG & 0.3 & 0.05 & Unstable & Unstable \\
\hline $450 \mathrm{~km}$ & CG & 0.3 & 0.05 & Unstable & Unstable \\
\hline $450 \mathrm{~km}$ & BC & 0.2 & 0.05 & Stable & Stable \\
\hline $450 \mathrm{~km}$ & AB & 0.3 & 0.1 & Unstable & Unstable \\
\hline $450 \mathrm{~km}$ & BC & 0.3 & 0.1 & Unstable & Unstable \\
\hline $450 \mathrm{~km}$ & CA & 0.3 & 0.1 & Unstable & Unstable \\
\hline $450 \mathrm{~km}$ & CAG & 0.2 & 0.05 & Stable & Stable \\
\hline $450 \mathrm{~km}$ & ABG & 0.4 & 0.05 & Unstable & Unstable \\
\hline $450 \mathrm{~km}$ & BCG & 0.4 & 0.05 & Unstable & Unstable \\
\hline $450 \mathrm{~km}$ & CAG & 0.4 & 0.05 & Unstable & Unstable \\
\hline $450 \mathrm{~km}$ & ABCG & 0.3 & 0.05 & Unstable & Unstable \\
\hline $600 \mathrm{~km}$ & AG & 0.2 & 0.05 & Unstable & Unstable \\
\hline $600 \mathrm{~km}$ & BC & 0.2 & 0.05 & Unstable & Unstable \\
\hline $600 \mathrm{~km}$ & CAG & 0.2 & 0.05 & Unstable & Unstable \\
\hline $750 \mathrm{~km}$ & AG & 0.2 & 0.05 & Unstable & Unstable \\
\hline $750 \mathrm{~km}$ & BC & 0.2 & 0.05 & Unstable & Unstable \\
\hline $750 \mathrm{~km}$ & CAG & 0.2 & 0.05 & Unstable & Unstable \\
\hline
\end{tabular}

where,

$t_{\mathrm{f}}$ is the time of fault inception.

$\mathrm{D}_{\mathrm{f}}$ is the duration of fault.

Table 3: Test results of the proposed scheme to faults at different fault inception times and different fault durations

\begin{tabular}{|l|l|l|l|l|l|}
\hline Fault location & Fault type & $\mathrm{t}_{\mathrm{f}}$ & $\mathrm{D}_{\mathrm{f}}$ & $\begin{array}{l}\text { Proposed } \\
\text { Scheme Output }\end{array}$ & $\begin{array}{l}\text { Time Domain } \\
\text { Simulation }\end{array}$ \\
\hline $300 \mathrm{~km}$ & AG & 0.1 & 0.1 & Stable & Stable \\
\hline $300 \mathrm{~km}$ & AG & 0.2 & 0.05 & Stable & Stable \\
\hline $300 \mathrm{~km}$ & AG & 0.2 & 0.2 & Unstable & Unstable \\
\hline $300 \mathrm{~km}$ & AG & 0.3 & 0.05 & Unstable & Unstable \\
\hline $300 \mathrm{~km}$ & AG & 0.4 & 0.1 & Unstable & Unstable \\
\hline $300 \mathrm{~km}$ & BC & 0.1 & 0.1 & Stable & Stable \\
\hline $300 \mathrm{~km}$ & BC & 0.2 & 0.05 & Stable & Stable \\
\hline $300 \mathrm{~km}$ & BC & 0.2 & 0.2 & Unstable & Unstable \\
\hline $300 \mathrm{~km}$ & BC & 0.3 & 0.05 & Unstable & Unstable \\
\hline $300 \mathrm{~km}$ & BC & 0.4 & 0.1 & Unstable & Unstable \\
\hline $300 \mathrm{~km}$ & CAG & 0.1 & 0.1 & Stable & Stable \\
\hline $300 \mathrm{~km}$ & CAG & 0.2 & 0.05 & Stable & Stable \\
\hline $300 \mathrm{~km}$ & CAG & 0.2 & 0.2 & Unstable & Unstable \\
\hline $300 \mathrm{~km}$ & CAG & 0.3 & 0.05 & Unstable & Unstable \\
\hline $300 \mathrm{~km}$ & CAG & 0.4 & 0.1 & Unstable & Unstable \\
\hline $300 \mathrm{~km}$ & ABCG & 0.1 & 0.1 & Unstable & Unstable \\
\hline $300 \mathrm{~km}$ & ABCG & 0.2 & 0.05 & Unstable & Unstable \\
\hline $300 \mathrm{~km}$ & ABCG & 0.2 & 0.2 & Unstable & Unstable \\
\hline $300 \mathrm{~km}$ & ABCG & 0.3 & 0.05 & Unstable & Unstable \\
\hline $300 \mathrm{~km}$ & ABCG & 0.4 & 0.1 & Unstable & Unstable \\
\hline
\end{tabular}


It is concluded from Table 3 that duration of fault is directly related to the angle difference between the generator and infinite bus $(\delta)$ which will affect the accelerating and decelerating area affecting the stability of the system, when $D_{f}$ increases for the same $t_{f}$ the system will tend to be unstable. It is also noted that when $t_{f}$ increases for the same $D_{f}$, the system will tend to be unstable, all cases are compared by TDS and give identical results.

\title{
6. Conclusions
}

This paper presents a transmission line protection scheme which uses measured values of the currents and voltages of the three phases of two buses (equivalent to PMU data) to detect the out-of-step condition. The proposed scheme is applicable to the protection of double-circuit transmission lines as well as regular single-circuit line. The Discrete Fourier Transform is used to transform the sampled data in phasor domain which is equivalent to PMU readings. The PMU has great potential to be a useful measurement unit to detect out of step conditions in the complex power system networks that are used today. The EAC is used and proved that it is an efficient method for determining the transient stability of a power system and detecting the out of step condition. Test results show that the proposed scheme is able to detect the out of step condition under different conditions with different fault types, different locations and different models of transmission line for a one machine against infinite bus or two machine system from the measured data equivalent to one PMU reading. The algorithm needs to be further developed to be able to detect out of step condition for multi-machine system, it would be interesting to make simulations on larger networks that include more generators and machines and to find possible nodes to implement PMUs.

\author{
Nomenclature \\ PMU Phasor Measurement Unit \\ GPS Global positioning system \\ DFT Discrete Fourier Transform \\ TDS Time Domain Simulation \\ $t_{f} \quad$ Time of fault inception \\ $D_{\mathrm{f}} \quad$ Duration of fault \\ EAC Equal-Area Criterion
}

\section{References}

Bhalja B., Maheshwari R., 2005. Philosophy of protection for multi-terminal and double-circuit lines, in: Proc. Int. Conf. Computer Applications in Electrical Engineering Recent Advances, Roorkee, India, vol. 1, pp. 582-588.

Berkestedt A. H., 2007. Phasor measurement based out-of-step detection, M. Sc. Thesis, Division of Electric Power Engineering, Department of Energy and Environment, Chalmers University of Technology, Göteborg, Sweden.

Benmouyal G., Schweitzer E.O., Guzmán A., 2002. Synchronized phasor measurement in protective relay for protection, control, and analysis of electric power systems, Schweitzer Engineering Laboratories, 29th Annual Western Protective Relay Conference, Spokane, Washington, October 22-24.

Bettiol A. L., Souza A., Todesco J. L. and Tesch, J. R. Jr. 2003. Estimation of critical clearing times using neural network, IEEE Bologna Power Tech Conference, Bologna, Italy, Vol. 3.

Bozchalui M. C., Sanaye-Pasand M., 2006. Out of step relaying using phasor measurement unit and equal-area criterion, IEEE Power India Conference..

Colvara L. D., 2009. Stability analysis of power systems described with detailed models by automatic method, International Journal of Electrical Power and Energy Systems, Vol. 31, No. 4, pp. 139-145.

Fang L. and Ji-lai Y., March 2009. Transient stability analysis with equal-area criterion directly used to a non equivalent generator pair, International Conference on Power Engineering, Energy and Electric Drives, Lisbon, Portugal, pp. 386-389.

Fouad A. A. and Vittal V., 1992. Power system transient stability analysis using the transient energy function method, PrenticeHall.

Grigsby L. L., 2007. Power system stability and control, CRC Press.

Hart D.G., Uy D., Gharpure V., Novosel D., Karlsson D. and Kaba M., 2001. PMUs - A new Approach to power network monitoring, ABB Review1.

Horowitz S., Phadke A., 1995. Power system relaying, 2nd ed., Research Studies/Wiley, New York.

IET, 1995. Electricity Training Association, Power System Protection, Vol. 2, Digital Protection and Signaling, IEE, London.

IEEE/CIGRE Joint Task Force, 2004. Definition and classification of power system stability, IEEE Transactions on Power Systems, Vol. 19, No. 3, pp. 1387-1401.

Karami A., 2011. Power system transient stability margin estimation using neural networks, International Journal of Electrical Power and Energy Systems, Vol. 33, No. 4, pp. 983-991.

Kundur P., 1994. Power system stability and control, McGraw-Hill.

Pavella M. and Murthy P. G., 1994.Transient stability of power systems: theory and Practice, John Wiley and Sons.

Pai M. A., 1989. Energy function analysis for power system stability, Springer. 
Phadke A. G., 1993. Synchronized phasor measurements in power systems, IEEE Computer Applications in Power, Vol. 6, No. 2, pp. 10-15.

Phadke A. G. and Thorp J. S., 2006. History and applications of phasor measurements, Virginia Tech, Blacksburg, Virginia, USA, PSCE.

Phadke A. G., Thorp J. S., 1991, Advances in electric power and energy conversion system dynamics and control, edited by C. T. Leondes, Academic Press.

Paudyal S., 2009. Out-of-step protection using energy equilibrium criterion in the time domain, M. Sc. Thesis, University of Saskatchewan.

Ree J.D.L., Centeno V., Thorp J.S. and Phadke A.G., June 2010. Synchronized phasor measurement applications in power systems, IEEE Transactions on Smart Grid, Vol. 1, No. 1, pp. 20-27.

Sachdev M., 1997. Advancements in microprocessor-based protection and communication, IEEE Tutorial Course Text, Publication No. 97TP120-0.

Stevenson W. D., Jr., 1986. Elements of power system analysis, $4^{\text {th }}$ Edition, McGraw-Hill Book Company.

Thorp J. S., Phadke A. G., Horowitz S. H. and Ekgovic M. M., May 1988. Some applications of phasor measurements to adaptive protection, IEEE Transactions on Power Systems, Vol. 3, No. 2, pp. 791-798.

Waiker D., Elangovan S., Liew A., 1996. Design, Implementation and performance evaluation of a new digital distance relaying algorithm, IEEE Trans. Power Syst.

Xue Y., Cutsem T. V. and Pavella M. A., 1989. Extended equal-area criterion justifications, generalizations, applications, IEEE Transactions on Power Systems, Vol. 4, No. 1, pp. 44-52.

Xue Y., Cutsem T. V. and Pavella M. A., 1988. Simple direct method for fast transient stability assessment of large power systems, IEEE Transactions on Power Systems, Vol. 3, No. 2, pp. 400-412.

Zadeha H. K. and Li Z., 2011. Phasor measurement unit based transmission line protection scheme design, Electric Power Systems Research, Vol. 81, No. 2, pp. 421-429.

\section{Biographical notes}

Almoataz Y. Abdelaziz was born in Cairo, Egypt, on September 14, 1963. He received the B. Sc. and M. Sc. degrees in electrical engineering from Ain Shams University, Cairo, Egypt in 1985, 1990 respectively and the Ph. D. degree in electrical engineering according to the channel system between Ain Shams University, Egypt and Brunel University, England in 1996. He is currently a professor of electrical power engineering in Ain Shams University. He was the head of consultant engineers of the electrical group in the General Directorate for Projects \& Maintenance, King Saud University, Riyadh, KSA from 2005 to 2007. His research interests include the applications of artificial intelligence to power systems and protection and new optimization techniques in power systems operation and planning. He has authored or coauthored more than 110 refereed journal and conference papers. Dr. Abdelaziz is a member of the editorial board and a reviewer of technical papers in several local and international journals. He is also a member in IET and the Egyptian Sub-Committees of IEC and CIGRE`. Dr. Abdelaziz has been awarded Ain Shams University Prize for distinct researches in 2002 and for international publishing in 2011, 2012.

Amr M. Ibrahim was born in Cairo, Egypt, on 1975. He received the B. Sc., M. Sc. and Ph. D. degrees in electrical engineering from Ain Shams University, Cairo, Egypt in 1998, 2003 and 2008 respectively. He is currently an assistant professor of electrical power engineering in Ain Shams University. His research interests include the applications of artificial intelligence to power systems and protection.

Zeinab G. Hasan was born in Cairo, Egypt, on October 1, 1985. She received the B. Eng. Degree (Honors) in electrical engineering from Ain-Shams University in Cairo, Egypt in 2007. She is now working for the M. Sc. degree in electrical engineering from Ain Shams University in Cairo, Egypt. Currently, she is working at The Higher Institute of Engineering and Technology, Fifth Settlement, Cairo. Her research interests include power system analysis and protection.

Received July 2012

Accepted October 2012

Final acceptance in revised form October 2012 